\title{
Combining the effects of undersized drilling and bone density on implant insertion torque
}

\author{
Bernardo Alievi Camargo, DDS, MS'; Daniel Becker Nunes, DDS²; Aloísio Oro Spazzin, DDS, MS, PhD³; Leonardo \\ Federizzi, DDS, MS4; Chirstian Schuh, DDS, MS ; Érica Alves Gomes DDS, MS, PhD \\ ${ }^{1}$ Faculdade Meridional - IMED, School of Dentistry, Department of Prosthodontics and Oral Implantology, Passo Fundo, RS, Brazil \\ ${ }^{2}$ Faculdade Meridional - IMED, School of Dentistry, Department of Prosthodontics and Oral Implantology, Passo Fundo, RS, Brazil \\ ${ }^{3}$ Faculdade Meridional - IMED, School of Dentistry, Department of Prosthodontics and Oral Implantology, Passo Fundo, RS, Brazil \\ ${ }^{4}$ Universidade de Ribeirão Preto - UNAERP, School of Dentistry, Department of Prosthodontics, Ribeirão Preto, SP, Brazil \\ ${ }^{5}$ Faculdade Meridional - IMED, School of Dentistry, Department of Prosthodontics and Oral Implantology, Passo Fundo, RS, Brazil \\ ${ }^{6}$ Universidade de Ribeirão Preto - UNAERP, School of Dentistry, Department of Prosthodontics, Ribeirão Preto, SP, Brazi
}

\begin{abstract}
Aim: This study evaluated the influence of surgical undersized drilling on insertion torque of an implant system at low bone density. Methods: Implant site preparations were made in two polyurethane foam blocks with different densities, where two preparation techniques were considered: Control group (C): conventional drilling, following the manufacturer's instructions; and Group (E): undersized drilling, experimental technique using a final surgical drill with reduced diameter. The artificial bone blocks were selected based on density: $D_{1}\left(0.64 \mathrm{~g} / \mathrm{cm}^{3}\right)$ and $D_{2}\left(0.32 \mathrm{~g} / \mathrm{cm}^{3}\right)$. Three groups were considered according to the preparation technique and bone density used $(n=10): C D_{1}$ - conventional drilling technique in artificial bone with higher density; $\mathrm{CD}_{2}$ - conventional drilling technique in artificial bone with lower density; and $\mathrm{ED}_{2}$ - undersized drilling in artificial bone with lower density. Externalhexagon implants $(11 \times 4 \mathrm{~mm})$ were inserted and the insertion torque values were measured using a digital torque-meter. Data were submitted to one-way ANOVA followed by Tukey's test $(\alpha=0.05)$. Results: The results showed significant statistical differences between groups $(p<0.001)$, where the highest insertion torque was found for the Group $\mathrm{CD}_{1}(48.9 \mathrm{Ncm})$ followed by Group $\mathrm{ED}_{2}(22.6$ $\mathrm{Ncm})$ and Group $\mathrm{CD}_{2}(11.7 \mathrm{Ncm})$. Conclusions: The undersized drilling technique for implant site preparation leads to increased insertion torque on low bone density.
\end{abstract}

Keywords: Dental implantation. Torque. Bone density. Drilling Techniques.

\section{Introduction}

Received for publication: December 19, 2016 Accepted: June 12, 2017

Correspondence to: Prof. Dr. Érica Alves Gomes Department of Prosthodontics, School of Dentistry University of Ribeirão Preto, UNAERP Av. Costábile Romano, 2.201, CEP 14096-900, Ribeirão Preto, SP, Brazil Tel.: + 55 (16) 3603-7000 E-mail: ericaagomes@yahoo.com.br
The insertion torque obtained during the surgical moment of implant placement is essential to improve the primary stability, and consequently, to generate a successful osseointegration, especially during the immediate loading procedure ${ }^{1,2}$. Primary stability is defined as the absence of implant movement achieved after implant placement, and it depends of the implant design, bone density and surgical preparation technique ${ }^{3,4}$. Additionally, a decreased insertion torque presents a higher risk of early implant failure considering an immediate loading, whereas high stability allows smaller micro-motions of the implant inside the bone providing good conditions for osseointegration ${ }^{5}$.

The bone density is one of the most important factors related to a higher insertion torque. Higher bone density creates greater bone-implant contact and consequently, it 
increases the primary stability. On the other hand, a low bone density is associated to a higher implant failure rate ${ }^{6,7}$. Clinical studies shows that implants placed in the jaw present higher survival rates compared to the ones placed on the maxilla ${ }^{8,9}$, especially when considered the maxillary posterior region witch usually presents a thinner cortical bone combined with thicker trabecular bone ${ }^{10}$. Clinically, the quality and quantity of bone are local factors that cannot be controlled; whereas, surgical technique and implant design may be changed to adapt specific bone situations and improve insertion torque ${ }^{1,11}$.

Several strategies have been proposed to improve implant insertion torque in low-density bone. Therefore, the undersized drilling technique recommends a site preparation smaller than the diameter of the implant, providing a press-fit situation in which strain propagates into the supporting bone. This so-called undersized drilling technique was introduced with the aim to locally optimize bone density and consequently improve the insertion torque and the primary stability of the implant ${ }^{2,12-14}$. This possibility becomes interesting mainly in situations of low bone density, where the direct contact with the implant surface will be smaller.

However, literature suggests that the use of undersized drilling technique may not fully compensate the effect of low bone density, once the factors related to implant diameter/length and bone density may also affect the level of implant insertion torque ${ }^{6}$. Therefore, the purpose of this study was to evaluate the influence of surgical undersized drilling on the insertion torque of an externalhexagon dental implant system at a lower bone density. The null hypothesis was that there would be no significant differences in the insertion torque regardless of the preparation technique used.

\section{Material and methods}

Three groups $(n=10)$ were considered according to the preparation technique (conventional drilling $\mathrm{x}$ undersized drilling) and two different bone densities (high density x low density) used, as described on Table 1.

Table 1 - The combination of the drilling technique and bone density

\begin{tabular}{lll}
\hline Group & Bone density $\left(\mathrm{g} / \mathrm{cm}^{3}\right)$ & Drilling technique \\
\hline $\mathrm{CD}_{1}$ & 0.64 & $\# 2.0 \mathrm{~mm}, \# 2 / 3$ pilot, \#3.0 mm, \#3.3 mm \\
$\mathrm{CD}_{2}$ & 0.32 & $\# 2.0 \mathrm{~mm}, \# 2 / 3$ pilot, \#3.0 mm, \#3.3 mm \\
$\mathrm{ED}_{2}$ & 0.32 & $\# 2.0 \mathrm{~mm}, \# 2 / 3$ pilot, \#3.0 mm
\end{tabular}

All implant preparations and insertions were made using a surgical hand-piece (SG20; NSK, Kanumashi, Japan) coupled to a surgical motor unit (Neosurg XT Plus; NSK) under plentiful and constant saline irrigation and at a constant speed of $800 \mathrm{rpm}$. A single calibrated and trained operator performed all the implant site preparations and implant insertions. It highlights that the artificial bone blocks were attached to a support jig to avoid movement during all procedures.

Implant site preparations were made in two rigid polyurethane foam blocks (Nacional Ossos, Jaú, SP, Brazil), with dimensions of $18 \times 13 \times 4 \mathrm{~cm}$; which were produced in conformity with ASTM F1839-97. The artificial bone blocks used in the present study were selected based on different densities, as following: $\mathrm{D}_{1}$ $\left(0.64 \mathrm{~g} / \mathrm{cm}^{3}\right)$ and $\mathrm{D}_{2}\left(0.32 \mathrm{~g} / \mathrm{cm}^{3}\right)$.

A total of thirty implant site preparations were performed using surgical drills (Neodent, Curitiba, PR, Brazil), where two preparation techniques were evaluated: one following the fabricant instructions (conventional drilling/control groups, C); and the other, using an experimental technique, with a reduced final surgical drill size (undersized drilling, E). First, the pilot holes were performed using a lance drill (2.0 mm of diameter, Neodent, Curitiba, PR, Brazil) in $11 \mathrm{~mm}$ of depth for all groups; and then, a final \#4.1 mm countersink drill (Neodent, Curitiba, PR, Brazil) was used in all groups following fabricant instructions.

For the conventional drilling (control groups $-\mathrm{C}$ ), the implant site preparations were performed using the drill sequence (Neodent, Curitiba, PR, Brazil), \#2.0 mm, \#2/3 pilot, \#3.0 mm,\#3.3 $\mathrm{mm}$ drills. While, for the undersized preparation (experimental group - E) it was used the same sequence of drills until the $\# 3.0 \mathrm{~mm}$ (i.e. the last one $\# 3.3 \mathrm{~mm}$ was not used). After that, externalhexagon implants (cylindrical shape and dimensions of $4.0 \mathrm{~mm}$ in diameter and $11.0 \mathrm{~mm}$ length; Titamax Ti Cortical; Neodent, Curitiba, PR, Brazil) were inserted and the final insertion torque, $(\mathrm{Ncm})$ was measured with a digital torque-meter that presents a 0.1-N.cm precision (TQ8800; Lutron, Taipei, Taiwan). The results were statistically analyzed by Kolmogorov-Smirnov test (data distribution test), and as they presented a parametric (normal) distribution the one-way ANOVA (analysis of variance) and the post-hoc Tukey's test were employed $(\alpha=0.05)$.

\section{Results}

Statistical data from insertion torque values are summarized in Figure 1. One-way ANOVA showed a statistically significant difference between groups $(p<0.001)$, where all of them were different from each other. The highest insertion torque was achieved on the group submitted to the conventional drilling technique at the higher density bone $\left(\mathrm{CD}_{1}, 48.9 \pm 9.3 \mathrm{Ncm}\right)$ followed by the undersized drilling technique at the low density bone $\left(\mathrm{ED}_{2}, 22.6 \pm 3.2 \mathrm{Ncm}\right)$; and the worst scenario was observed on the conventional drilling and low density bone $\left(\mathrm{CD}_{2}, 11.7 \pm\right.$ $2.8 \mathrm{Ncm})$.

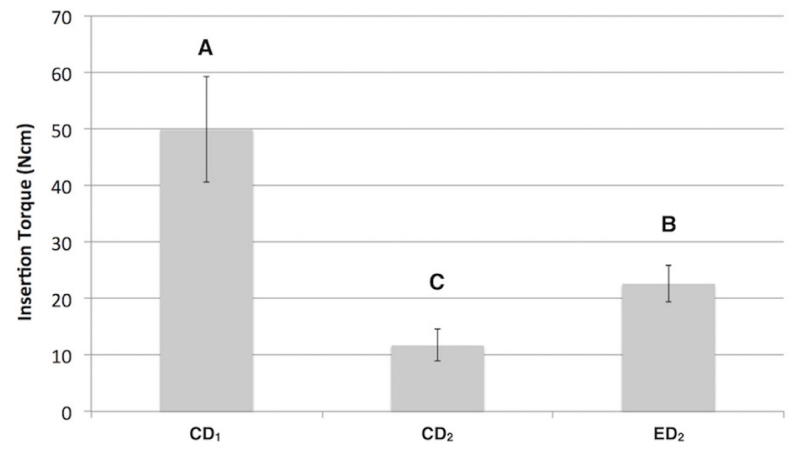

Figure 1 - Mean insertion torque values $(\mathrm{Ncm})$ for different experimental groups: control technique and higher bone density $\left(\mathrm{CD}_{1}\right)$; control technique and lower bone density $\left(\mathrm{CD}_{2}\right)$; and undersized drilling technique and lower bone density $\left(\mathrm{ED}_{2}\right)$. Different capital letters above the bars represent significant statistical difference between the groups $(\mathrm{p}<0.001)$. 


\section{Discussion}

Today, it lacks consensus regarding a standard experimental design to investigate the effect of implant site preparations. Different bone models based on cadaveric bone (acquired from tissue banks), synthetic blocks, and resin models have been described ${ }^{15}$. The American Society for Testing Materials (ASTM F-1839-08) has been considering the use of solid rigid polyurethane foam blocks as the gold standard materials for simulate artificial bone on laboratory tests, as they present similar mechanical properties to the human bone. Besides, they present the advantage of high structural homogeneity in comparison to the other alternatives (human cadaveric bone or animal bones). Thus, these artificial bone blocks have already been used successfully in previous studies ${ }^{4,15-20}$.

Concerning the evaluation method to assess the implant primary stability, several noninvasive techniques have been tested in scientific literature. Among all existing options the most reported in laboratory and clinical studies are the insertion torque and resonance frequency analysis ${ }^{4,21,22}$. The resonance frequency analysis use a particular device (Ostell), while the insertion torque is evaluated in the moment of implant placement using a surgical torque-meter, surgical motor, or digital torque meter. However, there is no consensus concerning which would be the more efficient method to evaluate these outcomes. Therefore, in the current study we opted to use the digital torque meter.

The null hypothesis was rejected, since the insertion torque is dependent of the technique for implant site preparation in low density bone. Our data support that the highest insertion torque mean $(48.9$ N.cm) was achieved with the group submitted to conventional drilling in the artificial bone with higher density $\left(C D_{1}\right)$; while, the group submitted to conventional drilling with lower bone density $\left(\mathrm{CD}_{2}\right)$ presented the lowest insertion torque mean $(11.7$ N.cm). Similar results were found in other studies ${ }^{4,19,23-25}$ where a positive relation between implant stability and artificial bone block density was noticed. Besides, Magno Filho et al. ${ }^{23}$ evaluating the insertion torque and resonance frequency analysis of implants placed in maxilla and mandible with different bone densities, observed higher implant insertion torque and resonance frequency analysis on most dense bone, elucidating a positive correlation between these factors.

When considering the undersized drilling, the results of this current study support that this technique leads to a higher insertion torque for low density bone $\left(\mathrm{ED}_{2}\right)$, in comparison to the conventional drilling technique (technique recommended by the manufacturer) at the same scenario $\left(\mathrm{CD}_{2}\right)$. These results are in agreement with a previous study ${ }^{26}$. However, it is important to emphasize that this technique (undersized drilling - ED $\mathrm{ED}_{2}$ still leads to lower insertion torque in comparison to the one obtained by conventional drilling technique at higher bone density $\left(\mathrm{CD}_{1}\right)$. Therefore despite it increases the insertion torque; it still does not fully compensate the lower density of the foam bone block.

Thus, undersized drilling of the implant site is shown as an efficient technique for lower density bone to ensure primary stability $^{27}$. However, a potential risk of bone necrosis has been assumed due to over compression inserted in bone tissue around of the implant ${ }^{28}$. On this sense, literature shows that this technique should be not the first choice in regions of higher density bones, which was the main reason why the current study did not simulated this scenario. Another factor that could influence the final insertion torque is the shape of the implant, where a previous study ${ }^{29}$ showed that tapered shape implants with surface treatments, leads to higher insertion torque in comparison to cylindrical ones with machined surface.

Despite the methodological differences presented between clinical and laboratorial studies, it becomes evident a strong correlation between surgical technique, bone density, insertion torque and primary stability of the implant. However, as other factors (different physical and biological features) may be involved in obtaining an adequate insertion torque and primary stability on a clinical scenario, it is still strongly recommended the execution of clinical studies evaluating technological innovations on regards of shape and surface treatments of dental implants aiming to achieve higher insertion torque especially in regions with lower density bone. Thus, within the limitations of this in vitro study and according to the obtained results, it may be concluded that the undersized drilling of the implant site preparation increased the insertion torque in lower bone density.

\section{References}

1. Heinemann F, Hasan I, Bourauel C, Biffar R, Mundt T. Bone stability around dental implants: Treatment related factors. Ann Anat. 2015 May;199:3-8. doi: 10.1016/j.aanat.2015.02.004.

2. Javed F, Ahmed HB, Crespi R, Romanos GE. Role of primary stability for successful osseointegration of dental implants: Factors of influence and evaluation. Interv Med Appl Sci. 2013 Dec;5(4):162-7. doi: 10.1556/IMAS.5.2013.4.3

3. Chong L, Khocht A, Suzuki JB, Gaughan J. Effect of implant design on initial stability of tapered implants. J Oral Implantol. 2009;35(3):130-5. doi: 10.1563/1548-1336-35.3.130. doi: 10.1563/1548-1336-35.3.130.

4. Mohlhenrich SC, Heussen N, Elvers D, Steiner T, Holzle F, Modabber A. Compensating for poor primary implant stability in different bone densities by varying implant geometry: a laboratory study. Int J Oral Maxillofac Surg. 2015 Dec;44(12):1514-20. doi: 10.1016/j. ijom.2015.08.985.

5. Trisi P, Berardi D, Paolantonio M, Spoto G, D’Addona A, Perfetti G. Primary stability, insertion torque, and bone density of conical implants with internal hexagon: is there a relationship. J Craniofac Surg. 2013 May;24(3):841-4. doi: 10.1097/SCS.0b013e31827c9e01.

6. Ostman PO, Hellman M, Wendelhag I, Sennerby L. Resonance frequency analysis measurements of implants at placement surgery. Int J Prosthodont. 2006 Jan-Feb;19(1):77-83.

7. Akkocaoglu M, Uysal S, Tekdemir I, Akca K, Cehreli MC. Implant design and intraosseous stability of immediately placed implants: a human cadaver study. Clin Oral Implants Res. 2005 Apr;16(2):202-9.

8. Jemt T, Stenport V. Implant treatment with fixed prostheses in the edentulous maxilla. Part 2: prosthetic technique and clinical maintenance in two patient cohorts restored between 1986 and 1987 and 15 years later. Int J Prosthodont. 2011 Jul-Aug;24(4):356-62.

9. Jemt T, Stenport V, Friberg B. Implant treatment with fixed prostheses in the edentulous maxilla. Part 1: implants and biologic response in two patient cohorts restored between 1986 and 1987 and 15 years later. Int J Prosthodont. 2011 Jul-Aug;24(4):345-55.

10. Shibli JA, Mangano C, Mangano F, Rodrigues JA, Cassoni A, Bechara $\mathrm{K}$, et al. Bone-to-implant contact around immediately loaded direct laser metal-forming transitional implants in human posterior maxilla. $\mathrm{J}$ 
Periodontol. 2013 Jun;84(6):732-7. doi: 10.1902/jop.2012.120126.

11. Friberg B, Ekestubbe A, Sennerby L. Clinical outcome of Branemark System implants of various diameters: a retrospective study. Int J Oral Maxillofac Implants. 2002 Sep-Oct;17(5):671-7.

12. Irinakis $\mathrm{T}$, Wiebe $\mathrm{C}$. Initial torque stability of a new bone condensing dental implant. A cohort study of 140 consecutively placed implants. J Oral Implantol. 2009;35(6):277-82. doi: 10.1563/AAIDJOI-D-09-00020.1.

13. Tabassum A, Meijer GJ, Wolke JG, Jansen JA. Influence of surgical technique and surface roughness on the primary stability of an implant in artificial bone with different cortical thickness: a laboratory study. Clin Oral Implants Res. 2010 Feb;21(2):213-20. doi: 10.1111/j.16000501.2009.01823.x.

14. Bilhan H, Geckili O, Mumcu E, Bozdag E, Sunbuloglu E, Kutay $O$. Influence of surgical technique, implant shape and diameter on the primary stability in cancellous bone. J Oral Rehabil. 2010 Dec;37(12):900-7. doi: 10.1111/j.1365-2842.2010.02117.x.

15. Mohlhenrich SC, Modabber A, Steiner T, Mitchell DA, Holzle F. Heat generation and drill wear during dental implant site preparation: systematic review. Br J Oral Maxillofac Surg. 2015 Oct;53(8):679-89. doi: 10.1016/j.bjoms.2015.05.004.

16. Mohlhenrich SC, Heussen N, Loberg C, Goloborodko E, Holzle F, Modabber A. Three-Dimensional Evaluation of Implant Bed Preparation and the Influence on Primary Implant Stability After Using 2 Different Surgical Techniques. J Oral Maxillofac Surg. 2015 Sep;73(9):1723-32. doi: 10.1016/j.joms.2015.03.071.

17. Wu SW, Lee CC, Fu PY, Lin SC. The effects of flute shape and thread profile on the insertion torque and primary stability of dental implants. Med Eng Phys. 2012 Sep;34(7):797-805. doi: 10.1016/j. medengphy.2011.09.021.

18. Hsu JT, Huang HL, Chang CH, Tsai MT, Hung WC, Fuh LJ. Relationship of three-dimensional bone-to-implant contact to primary implant stability and peri-implant bone strain in immediate loading: microcomputed tomographic and in vitro analyses. Int J Oral Maxillofac Implants. 2013 Mar-Apr;28(2):367-74. doi: 10.11607/ jomi.2407.

19. Wang TM, Lee MS, Wang JS, Lin LD. The effect of implant design and bone quality on insertion torque, resonance frequency analysis, and insertion energy during implant placement in low or low- to mediumdensity bone. Int J Prosthodont. 2015 Jan-Feb;28(1):40-7. doi: 10.11607/ijp.4063.
20. Hsu JT, Fuh LJ, Tu MG, Li YF, Chen KT, Huang HL. The effects of cortical bone thickness and trabecular bone strength on noninvasive measures of the implant primary stability using synthetic bone models. Clin Implant Dent Relat Res. 2013 Apr;15(2):251-61. doi: 10.1111/j.1708-8208.2011.00349.x.

21. Suer BT, Yaman Z, Buyuksarac B. Correlation of Fractal Dimension Values with Implant Insertion Torque and Resonance Frequency Values at Implant Recipient Sites. Int J Oral Maxillofac Implants. 2016 Jan-Feb;31(1):55-62. doi: 10.11607/jomi.3965.

22. Wang R, Eppell SJ, Nguyen C, Morris N. Relative contribution of trabecular and cortical bone to primary implant stability: an in vitro model study. J Oral Implantol. 2015 Apr;42(2):145-52. doi: 10.1563/ aaid-joi-D-14-00322.

23. Magno Filho LC, Cirano FR, Hayashi F, Feng HS, Conte A, Dib LL, et al. Assessment of the correlation between insertion torque and resonance frequency analysis of implants placed in bone tissue of different densities. J Oral Implantol. 2014 Jun;40(3):259-62. doi: 10.1563/AAID-JOI-D-11-00183.

24. Herekar M, Sethi M, Ahmad T, Fernandes AS, Patil V, Kulkarni H. A correlation between bone (B), insertion torque (IT), and implant stability (S): BITS score. J Prosthet Dent. 2014 Oct;112(4):805-10. doi: 10.1016/j.prosdent.2014.02.011.

25. Degidi M, Daprile G, Piattelli A. Primary stability determination by means of insertion torque and RFA in a sample of 4,135 implants. Clin Implant Dent Relat Res. 2012 Aug;14(4):501-7. doi: 10.1111/j.17088208.2010.00302.x.

26. Coelho PG, Marin C, Teixeira HS, Campos FE, Gomes JB, Guastald $F$, et al. Biomechanical evaluation of undersized drilling on implant biomechanical stability at early implantation times. J Oral Maxillofac Surg. 2013 Feb;71(2):e69-75. doi: 10.1016/j.joms.2012.10.008.

27. Al-Marshood MM, Junker R, Al-Rasheed A, Al Farraj Aldosari A, Jansen JA, Anil S. Study of the osseointegration of dental implants placed with an adapted surgical technique. Clin Oral Implants Res. 2011 Jul;22(7):753-9. doi: 10.1111/j.1600-0501.2010.02055.x.

28. Fanuscu MI, Chang TL, Akça K. Effect of surgical techniques on primary implant stability and peri-implant bone. J Oral Maxillofac Surg 2007;65 (12):2487-91.

29. Dos Santos MV, Elias CN, Cavalcanti Lima JH. The effects of superficial roughness and design on the primary stability of dental implants. Clin Implant Dent Relat Res. 2011 Sep;13(3):215-23. doi: 10.1111/j.1708-8208.2009.00202.x. 